Розглянуто питання теоретичного обтрунтування варіантів вибору оптимальної стратегії інтеграції аграрного підприемства до оптового ринку із застосуванням методологічного інструментарію некооперативної теорії ігор. Запропоновано моделювання поведінки аграрного підприемства на ринку, иляхом досягнення рівноваги Неша за різних сценаріїв дій конкурентів і обсягів інформащї про ринкові умови.

Обгрунтовано методику застосування ітераційних алгоритмів для обчислення рівноваг $у$ загальному класі неквадратичних опуклих багатогранників для формування методик $i$ побудови алгоритмів поведінки аграрних підприємств у ринковій діяльності. Визначено, що в реальних умовах діяльності аграрного підприємства на оптовому ринку прийняття рімень відбувається паралельно. Нляхом комплексного використання чисельних методів на основі розв'язання задач по оптимізацї гарантуеться плавне зближення з рівновагою Неша. При вирішенні таких задач гра може мати множинні ізольовані рівноваги Неша, якщо у гравців є неквадратичні функції виплат. 3 цього визначаються результати локальної конвергенціі, тому що в неквадратичних завданнях глобальні результати піддаються сильним обмеженням. Однак існує зв'язок з напівглобальною практичною асимптотичною стабільністю, якщо у гравців є квадратичні функиії виграшу. Для неквадратичних функцій виграшу показано, що збіжність зміщена пропорційно амплітудам сигналів збурень $і$ третім похідним функцій виграшу $і$ відповідає цьому зміщенню в чисельному прикладi.

Визначено, що за умови часткової інформачії про стан ринку стратегія навчання, розроблена відповідно до основних положень теорії ігор, залишаеться привабливою. Застосування визначеної стратегї дій підприемству поліпшити своє початкове становище, вимірюючи тільки власні значення виграшу $i$ не застосовуючи оцінки потенційно невизначених параметрів. Запропоновано використання прикладного інструментарію теорії ігор для визначення оптимальної стратегї дій аграрного підприємства для задач інтегращї його до оптового ринку овочевої продукції

Ключові слова: теорія ігор, стратегія дій, аграрне підприємство, оптовий ринок, рівновага Неша
UDC: $338.439 .5: 517.97$

DOI: $10.15587 / 1729-4061.2019 .187844$

\title{
OPTIMIZING THE STRATEGY OF ACTIVITIES USING NUMERICAL METHODS FOR DETERMINING EQUILIBRIUM
}

I. Sievidova

Doctor of Economic Sciences, Associate Professor*

E-mail: sevidova.ia@gmail.com

T. O l i y n y k

Doctor of Economic Sciences, Professor**

O. Mand y ch

Doctor of Economic Sciences, Professor*

T. Kvy a t ko

$\mathrm{PhD}$ *

I. Rom an i u k $\mathrm{PhD*}$

L. Leshchenko $\mathrm{PhD} * *$

S. Vy noh radenko

$\mathrm{PhD}$, Associate Professor

Department of Geodesy, Cartography and Geoinformatics***

S. PI y h u n

Postgraduate Student**

*Department of Marketing and Media Communications

Kharkiv Petro Vasylenko National Technical

University of Agriculture

Alchevskykh str., 44, Kharkiv, Ukraine, 61002

**Department of Applied Economics and International

Economic Relations***

***Kharkiv National Agrarian University named after V. V. Dokuchaiev

p/o “Dokuchaevske-2", Kharkiv dist., Kharkiv reg., Ukraine, 62483

\section{Introduction}

One can consider trends in the development of economy in the wholesale market, including a trade between the two countries, as a negotiation problem. Such interpretation of the classic economic problem exists in many forms, such as bargaining, double-sided monopoly, etc. One can also consider it as a two-player non-zero game. There are several general assumptions about the behavior of a single player or a group under certain economic conditions in such interpretation.

One can define the wholesale market of vegetables as a market of pure competition. Different definitions are used to define the same concept in today's economy. For example, "perfect competition" and "pure competition". This is a classic exchange problem that was considered within the framework of double-sided monopoly models, which aims to maximize both combined profits of oligopolists' union and profits of each of participants.

Because vegetable products are essentially homogeneous, end buyers always have information on the level of prices and choose market players with lower prices. Agricultural companies are also aware in the process of selling of their products that all end buyers have information on current prices. Therefore, they will not try to set higher prices, 
since buyers will simply choose products of other sellers. Of course, the real market situation looks a bit different, so the price level for vegetable products presented in the market by a large number of enterprises and private producers may have slight variations due to a slightly different quality of the presented products and a volume of a product batch. The difference is not significant.

A mathematical model has been constructed for market development to achieve the Nash equilibrium for a theoretical explanation of the choice of the optimal strategy for integration of an agricultural enterprise into the wholesale market. The base of J. Nash's theory is the assumption that each participant of a trade relationship acts independently, without cooperation or communication with other participants. Initially, the Nash's equilibrium concept was used in mathematical programming (in multicriteria optimization and theory of static games), where Nash equilibrium solutions often arose at saddle points of the payoff function. Consequently, researchers generalized the concept for differential games and implemented it as a strategy of Nash equilibrium management. However, since there is one player - it is an agricultural enterprise, which tries to integrate into the market, and another player - it is actually the market itself, many problems remain unresolved. Therefore, one shall use the desire of each agrarian enterprise to maximize its profit in the calculation of the strategy in the mathematical model, considering that there is almost no probability for an agrarian enterprise that the other party will not meet terms of the agreement.

The study is relevant given the requirements to improve efficiency in forming an optimal strategy for integration of an agricultural enterprise in the wholesale market of vegetable products using methodological tools of the game theory.

\section{Literature review and problem statement}

No agrarian enterprise or private producer can set a higher price than other market participants in the wholesale market of pure competition, which is the market of vegetable products in theory. The key problems in functioning of the industry are determination of a direction of development and formation of an optimal activity strategy for agricultural enterprises [1].

Researchers studied scenarios of various strategies of enterprise activity in the market, such as a Cournot model, a fictitious game strategy, a dynamic version of fictitious game and a gradient response and algorithms of synchronous distributed for many years [2-6]. Other approaches made possible to identify this typical situation as an exchange with a non-zero total sum [7].

Most algorithms aimed at achievement of the Nash equilibrium require modeling of information on a game and suggest that players can observe actions of other players. Two classic examples are the best answer and fictitious game strategies, where each player chooses an action that maximizes his win based on actions of other players. Authors of paper [8] investigated existence of the Nash equilibrium for the repetitive extended duopoly model of Bertrand's price competition, which is a special repetitive game. However, it is an idealized approach to the problem of trade competition in the market. It implies perfect rationality of parties, equality in trading skills and that each of players has full knowledge of a potential and advantages of the other player.
There was an algorithm for search for the Nash equilibrium for an aggregation game developed in work [9]. The algorithm has two interconnected dynamics. They predicted dynamics of gradient playback to search for the equilibrium with locally constrained sets of strategies [9] and distributed average tracking dynamics to evaluate aggregation [10]. In addition, paper [11] showed how to apply the dynamics of the distributed average tracking to the equilibrium by the weight of an oriented graph, which improves a learning algorithm. However, distributed algorithms made possible to achieve the equilibrium only by the speed, which was clearly limited by the structure of a graph, as distributed algorithms are asymptotic in nature.

Work [12] showed that the result of a convergence was present if a matrix met the Hurwitz criterion for stability for any given local diagonal dominance condition, then such a game could not have any asymmetric equilibria. However, such assumption made convergence possible and created a potentially complex dependency on an unknown game model and parameter selection.

Authors of paper [13] performed search for a strategy of equilibrium control in a differential game with a non-zero sum in a finite time by reduction of the game to a series of problems of optimal control and further application of iterative processes of the maximum principle. Boundary conditions usually create a barrier to the evolution of decision-making methods in a situation where some players have to enter their predetermined states and, at the same time, choose their strategies to maintain equilibrium by the end of the game. The authors of the paper obtained an iterative algorithm for the search of equilibrium control implemented without use of usual methods of the game theory.

Work [14] studied extreme strategies of resources distribution between alliance partners, including equilibrium strategy, proportional strategy, greedy strategy, and random strategy. Comparing advantages and disadvantages, it determined which strategy was expedient to apply in the investment decision-making process for an enterprise. There was an experimental model established and simulated for each strategy. And the conclusion was that, most often, a greedy strategy based on Rado-Edmonds algorithm provided the best performance. However, as the authors noted, some parameters of the experimental environment were random. Thus, the conclusions may not be applicable to all cases. In addition, a partnership game between two players still has many additional factors to consider, and this model provided only some experimental conclusions at a few theoretical points.

Researchers considered a theory of hyperrational choice based on the Nash concept. It is possible to divide the Nash equilibrium into three classes. The first class is equilibrium considered based on a personal profit. The second class is an equilibrium chosen by the profit or loss of other players. The third class is equilibrium considered based on of the individual profit and loss or profit of other players at the same time. Thus, authors of paper [15] explained a behavior of a wise person, who considered a profit or loss of others in addition to individual profit, using the theory of hyper-rational choice. This new concept may describe some types of human behavior well. On the contrary, for economic tasks, such as problems of integration of an enterprise in the wholesale market, it is more appropriate to consider the first type of an equilibrium with achievement of profit maximization. 
Work [16] investigated a potential function that guarantees one and only one Nash equilibrium when such a function is not strictly concave and there is no ensuring of existence of a maximum. It presented conditions of sufficiency for balanced potential games for two players when sets of strategies are valid Hilbert spaces. The work illustrates a class of games in finite-dimensional spaces, but this is crucially dependent on smoothness of the potential. There is no guarantee for uniqueness of the Nash equilibrium for examples where the potential is not smooth, even if it is strictly concave.

Paper [17] showed that the problem of achievement of the Nash equilibrium, as a kind of combination of strategies, relates to many important problems of mathematics, economics, and engineering technologies. A generalized game model plays an important role in tasks of management of the economy for proof of the existence of a general equilibrium. However, many economic problems boil down to nonlinear problems, which are denoted by the utility function without the advantage of infinite dimensional order. The traditional model of a general game cannot deal with problems such as utility function without an advantage, an incomplete advantage, a space with infinite order or nonlinear problems. Since there are no ready-made methods for solution of problems, we need new research methods.

Thus, it is advisable to use numerical utility to determine an optimal strategy for integration of agricultural enterprises in the wholesale market of vegetable products. One should form a mathematical model according to numerical utility using numerical values of utility to represent advantages of each player. In this case, each player, which participates in a game, will try to maximize his payoff.

Study [18] determined the Nash equilibrium in a bi-matrix game. The authors used economic indicators of enterprise profitability and market indicators for the assessment. There were great difficulties in assessment of a level of value for game matrices in the described model. Assessment of a profit among indicators was very difficult while performing the work. The obtained results highlighted the existence of at least one equilibrium point, except for taking into account a certain criterion for obtaining the Nash equilibrium point for mixed strategies.

Paper [19] investigated games with a total prize greater than zero [19]. It showed that such class of games was large enough to support any positive payout to players, with a total lower value of a prize. This may be the result of the Nash unique equilibrium with a pure strategy for correctly selected efficiency parameters. The equilibrium leads to the division of a prize into positive winning share for players whose sum does not exceed a total payoff and the residual share, which is lost due to the dispersion of rent, in such competition. However, the study on algorithms of behavior of an agricultural enterprise requires an analysis of the equilibrium state for a given specification of functions, that is, a strategy of behavior depending on efforts of players.

Authors of work [20] analyzed the Cournot Nash equilibrium point and local stability. They showed that variability caused by tangential bifurcation is characteristic to a chaotic behavior. The study showed that inappropriate speed of correction of player behavior may be one of the reasons that he becomes more vulnerable.

There was introduction of matrix games with zero-sum from two persons with fuzzy payoffs and different types of equilibrium strategies for fuzzy games. Paper [21] investigated the connection between parametric bi-matrix games and Nash equilibrium strategies and determined that there is at least one equilibrium strategy by Pareto-Nash equilibria in a fuzzy game in a zero-sum game [21].

Boundary norms of substitution tend to become equal between countries at a certain internal Nash equilibrium in the domestic market for two products. This can happen only if distribution of contributions, which is the equilibrium distribution, is also optimal by Pareto distribution [22].

Authors of work [23] proposed methods for calculation of the lower and upper bounds of the price of stability for a class of balanced games in the overloaded state with polynomial delays with negative coefficients. The upper bound on the value of the price of stability is the Nash equilibrium in this case. However, there was a global minimizer of Rosenthal potential used to determine the Nash equilibrium state [24]. That is, researchers used a potential method, which we can apply to potential games only, to reflect upper boundaries of the price of stability.

There was comparison of the approach with vectors of the sequence of advantages and the existing method for calculation of the Nash equilibria in the game theory performed [25]. The study showed an equation with a fixed point is equivalent to determination of the equilibrium of a group solution. However, the approach is more complex temporarily than the classic method of the best answer.

One understands the value of research findings for the theory and practice of strategic management of integration processes of agricultural enterprises. However, one should note that some aspects of the problem remain insufficiently studied. We need deeper research on methodological provisions of achievement of the Nash equilibrium in static and non-cooperative games. The essence of the research is proposal of methodological approaches to modeling the strategies of integration of agrarian enterprises into the wholesale agricultural market under different scenarios for achieving the Nash equilibrium. A systematic study on processes of choosing of an optimal strategy for agricultural enterprises in the wholesale market in today's conditions is important in theoretical and practical aspects. Therefore, it is necessary to study tools of strategic management and determine optimal algorithms of behavior of agricultural enterprises.

\section{The aim and objectives of the study}

The aim of this study is to construct an algorithm to form and select an optimal strategy for integration of an agrarian enterprise in the wholesale market of vegetable products based on applied game theory tools, modeling of behavior of producers in the market, achievement of the Nash equilibrium under different scenarios of behavior of competitors and volumes of information on market conditions.

We set the following tasks to achieve the objective:

- construction of an algorithm to optimize the strategy of behavior of producers in the market under different scenarios of behavior of competitors by achieving the Nash equilibrium;

- experimental research on application of iterative algorithms to calculate equilibria based on known solutions to optimization problems. 


\section{The algorithm to solve the problem on optimizing a behavior of players in the presence of risks by achieving the Nash equilibrium}

The most anticipated area of application of the theory of non-cooperative games is a study on negotiations, which involve several parties, with established rules of the game. However, complexity of mathematical work required the for full study increases quite quickly with an increase in the complexity of the game; so, the analysis of the game is very complex. It is possible only with the use of approximate calculational methods [26].

We define a static non-cooperative play as a situation, which includes three components: unlimited quantity of players $n$, an action set $\left(A_{i}\right), i \in n$ and auxiliary functions $\left(U_{i}\right)$, $i \in n$. It is necessary to define auxiliary components, such as information sets, time, or history (that is, sets of past actions) displayed in the utility function, as a part of the game, additional components, in the dynamic [27].

The concept of an equilibrium point is a fundamental element of the theory. The concept gives a generalization of the concept of a resolution of a zero-sum game with two persons. It turns out that a set of equilibrium points of a zero-sum game with two persons is simply a sum of all pairs of opposite "optimal strategies". In J. Nash's theory, the best alternative to a negotiated agreement is the most profitable alternative to a participant's actions, in case if negotiations fail and it is not possible to reach an agreement.

Solving the problems on representing an optimal strategy for activity of each enterprise requires calculations using special methods. It is necessary to consider a cost of production and a time value of money (products turnover) for an enterprise involved in the sale of products on the market.

Therefore, a game of this type is a game that includes $n$ players, each of which is connected to a finite set of pure strategies. As well as $p_{i}$ function, which displays a set of all $n$-sets of pure strategies in real numbers, corresponds to each i player.

A mixed $i$ player strategy will be a set of non-negative numbers, which have a unit sum and are in unambiguous correspondence to its pure strategies, in modeling of a market situation. There is $S_{i}=\sum_{a} c_{i a} \pi_{i a}$, where $c_{i a} \geq 0$ and $\sum_{a} c_{i a}=1$ to define such mixed strategy, where defined $\pi_{i a}$ are pure strategies of $i$ player. Next, one considers $S_{i}$ set as points in a simplex with vertices of $\pi_{i a}$ set. One can consider the simplex as a convex subset of a real vector space, which gives a natural linear combination process for mixed strategies [28].

We use $a, b, c$ notations to denote different businesses, and $\alpha, \beta, \gamma$-to denote appropriate pure strategies in the calculations. $S_{i}, T_{i}, K_{i}$ designations denote respectively mixed strategies; $\pi_{i a}$ is $\alpha$-pure strategy of the $i$-th enterprise. The payoff function, $P_{i}$, used in the definition of the final game above, has the united extension on $n$-sets of mixed strategies linear by mixed strategy of each player [ $n$-linear]. We denote these strategies using $P_{i}$ and record $P_{i}\left(S_{1}, S_{2}, \ldots, S_{n}\right)$.

$\$$ function determines $n$-set of mixed strategies and if $\$=\left(S_{1}, S_{2}, \ldots, S_{n}\right)$, then $P_{i}(\$)$ will determine $P_{i}\left(S_{1}, S_{2}, \ldots, S_{n}\right)$. We will also consider such $n$-set, $\$$, as a point in a vector space, a space of productions of vector spaces containing mixed strategies.

The set of all such $n$-sets forms a convex polyhedron, a product of simplexes, which represent mixed strategies. In this case, one can define an equilibrium point in $n$-tuple $\$$ when the following equation is correct for each $i$ player:

$$
P_{i}(\$)=\max _{a l l} x_{i}\left[p_{i}\left(\$ ; r_{i}\right)\right] .
$$

$S_{i}$ mixed strategy uses a pure $\$$ strategy $\$$ if

$$
S_{i}=\sum_{\beta} c_{i \beta} \pi_{i \beta}
$$

and $c_{i a} \geq 0$. If $\$=\left(S_{1}, S_{2}, \ldots, S_{n}\right)$, and $S_{i}$ uses $\pi_{i a}$, it follows that $\$$ also uses $\pi_{i a}$. From the linearity $P_{i}\left(S_{1}, S_{2}, \ldots, S_{n}\right)$ in $S_{i}$ [28],

$$
\max _{a l l}\left[p_{i}\left[p_{i}\left(\$ ; r_{i}\right)\right]=\max _{a}\left[p_{i}\left(\$ ; \pi_{i a}\right)\right] .\right.
$$

We define $P_{i a}(\$)=p_{i}\left(\$ ; \pi_{i a}\right)$. Then we obtain the following trivial necessary and sufficient condition for $\$$ to be the equilibrium point [28]:

$$
\begin{aligned}
& P_{i}(\$)=\max _{\alpha} p_{i \alpha}(\$) . \\
& \text { If } \$=\left(S_{1}, S_{2}, \ldots, S_{n}\right) \text { and } \\
& S_{i}=\sum_{a} c_{i a} \pi_{i a},
\end{aligned}
$$

then

$$
P_{i}(\$)=\sum_{a} c_{i a} p_{i a}(\$)
$$

therefore, to save (3), one must have $c_{i a}=0$ each time when $p_{i a}(\$)<\max _{\beta} p_{i \beta}(\$)$, that is, $\$$ does not use $\pi_{i a}$, unless it is not an optimal pure strategy for $i$ player. Based on the above: if $\pi_{i a}$ is used in $\$$, then $p_{i a}(\$)<\max _{\beta} p_{i \beta}(\$)$, is one more necessary and sufficient condition for the equilibrium point. As one can express $\left(P_{i}(\$)\right)$ criterion for the equilibrium point equation by equating of $n$-pairs of continuous functions on a space of $n$-tuples $\$$ equilibrium points, obviously, form a closed subset of this space [28].

Let us consider conditions of application of these theorems for determining an optimal strategy of actions of an agricultural enterprise, which enters the wholesale market of vegetable products. Obviously, when a certain agricultural enterprise is just appearing on the market, the price of its products in the market is fixed. This state of affairs corresponds to the conditions of perfect competition when certain market players do not have a decisive influence on a price of products [29].

At best, von Neumann's theory considers only a rather partial view of such games: games where transactions, negotiations and side payments between players are possible. However, in many situations analyzed, relationships between wholesale market players do not relate to this type of relationship [30]. There was further development of von Neumann's theories in the form of various attempts to distinguish between non-cooperative and cooperative games [31]. There are no connections between players in non-cooperative games, in particular, they cannot make side-payment agreements. One defines non-cooperative games as the main ones and reduce types of cooperative games to non-cooperative ones. One can achieve this by inclusion of negotiations of a cooperative game as formal moves in a non-cooperative game (actions such as offering a side payment from one player to another).

We call the strategy of players, which consists of choosing an action from $X_{i}$ set, a pure strategy. A strategy may be 
more complicated than just choosing of one of elements of $X_{i}$ set of actions in case of construction of a normal form of game by its expanded form. One should remember that for nature made moves, there is a likelihood of one or another of its "move" indicated in games in the expanded form. Similarly, players may not choose a single action in each situation, but choose one action with a certain probability. Then one should describe a choice of a player by probabilistic distribution by a set of actions possible in this game situation. It is called a mixed strategy. Studies showed that such behavior can lead a player to a more profitable distribution of benefits in some situations. Each such event is essentially a separate game, and its result influences formation of a strategy for a next round [32].

Enterprises implement real-time optimization strategies in the absence of any knowledge of modeling information, such as consumer preference, total demand or marginal cost, or price of competitors. Implementation of Nash strategies implies a deterministic search for extremum with sinusoidal perturbations to determine an acceptable range of a level of selling prices.

The Nash search strategy is necessary for stable achievement of the Nash equilibrium in non-cooperative games. Players do not need to know a mathematical model of their payoff functions or a basic model of a game. They only need to measure their own payoff values at determination of their actions over a specified period, which classify this strategy as learning [33].

\section{Application of iterative algorithms to search for the Nash equilibrium to forecast a player's behavior}

Under conditions of cooperative games, when there are $n$-players in a game, they can form coalitions in some way. Thus, they have so-called binding agreements between players. All players must strictly adhere to arrangements according to rules of a game. The consequences of the arrangements are formation of alliances between players (coalition formation), and accordingly, a part of an income goes from one player to another. The aspect of cooperative games, which deals with division of payoff (income) received by a coalition among its players is important for evaluation of effectiveness of a merger.

A game achieves the Nash equilibrium by all means only if each player knows both his marginal cost and price and the same indicators for the other player in the previous iteration step in a standard scheme of parallel action upgrade. Inclusion of indicators of total demand and preferences of a consumer in the calculation is also a necessary condition.

Competing for profit, companies that are $P_{1}$ i $P_{2}$ players, respectively, set their prices $-u_{1}$ and $u_{2}$ in a non-cooperative game. Each enterprise's profit is a product of a number of $s_{i}$ units sold and a profit per unit of production, which is also a difference between a level of $u_{i}$ selling price and $m_{i}$ marginal or production value of a product. In mathematical terms, one can model and express a profit by function:

$$
J_{i}(t)=s_{i}(t)\left(u_{i}(t)-m_{i}\right),
$$

where $s_{i}$ is the number of products sold, $m_{i}$ is the marginal cost and $i \in(1,2)$ for $P_{1}$ and $P_{2}[28]$.
To model the overall market behavior, we explored a model where a consumer prefers $P_{1}$ product, but he is ready to buy $P_{2}$ product, if its $u_{2}$ price will be sufficiently lower than $u_{1}$ price. Further, we modeled a sales level for each enterprise as [28]:

$$
\begin{aligned}
& S_{1}(t)=S_{d}-S_{2}(t), \\
& S_{1}(t)=\frac{1}{p}\left(u_{1}(t)-u_{2}(t)\right) .
\end{aligned}
$$

We take a fixed $S_{d}$ total consumer demand to simplify calculations, and quantified consumer preferences for $P_{1}$ as $p>0$. According to the results of modeling of the overall level of sales for each enterprise, it was determined that inequalities $u_{1}>u_{2}$ and $\left(u_{1}-u_{2}\right) / p<S_{d}$. are satisfied.

Applying (5) and (6) to the calculation (4), we obtain a formula for calculation of profit expressed by the quadratic functions of prices [28]:

$$
\begin{aligned}
& J_{1}=\frac{-u_{1}^{2}+u_{1} u_{2}+\left(m_{1}+S_{d} p\right) u_{1}-m_{1} u_{2}-S_{d} p m_{1}}{p}, \\
& J_{2}=\frac{-u_{2}^{2}+u_{1} u_{2}-m_{2} u_{1}+m_{2} u_{2}}{p} .
\end{aligned}
$$

And then we determine the Nash equilibrium [28]:

$$
\begin{aligned}
& u_{1}^{\prime \prime}=\frac{1}{3}\left(2 m_{1}+m_{2}+2 S_{d} p\right), \\
& u_{2}^{\prime \prime}=\frac{1}{3}\left(m_{1}+2 m_{2}+S_{d} p\right) .
\end{aligned}
$$

If $m_{1}=m_{2}$, then the constraints $u_{1}>u_{2}$ and $\left(u_{1}-u_{2}\right) / p<S_{d}$ are satisfied by the Nash equilibrium, and $m_{1}-m_{2}$ lies in $\left(-S_{d} p, 2 S_{d} p\right)$ interval.

To determine the Nash equilibrium $u^{\prime \prime}=\left[u_{1}^{\prime \prime}, \ldots, u_{n}\right]^{\mathrm{T}}$, for a game with n-players [28]:

$$
\begin{aligned}
& J_{i}\left(u_{j}^{\prime \prime}, u_{-i}^{\prime \prime}\right) \geq J_{i}\left(u_{i}, u_{-i}^{\prime \prime}\right), \\
& \forall u_{i} \in U_{i}, \quad i \in\{1, \ldots, N\},
\end{aligned}
$$

where $J_{i}$ is the $i$ player's payoff function, $u_{-i}$ is his action, $U_{i}$ is the set of actions and $u_{-i}$ denotes actions of other players. Therefore, no player has an incentive to dismiss his actions unilaterally. Ideally, $U_{1}=U_{2}=R_{+}$, where $R_{+}$denotes a set of positive real numbers.

There is no need for any market modeling information, such as $p$ consumer preference, $S_{d}$ total demand, or marginal cost, or a third-party price, to implement such strategy of achievement of the Nash equilibrium. Agricultural enterprises implement non-model optimization in real time of strategy action in the market, for example, deterministic search for extremes with sinusoidal perturbations to set their prices at the optimal level. In particular, $P_{1}$ and $P_{2}$ set their $u_{1}$ and $u_{2}$ prices according to a time-varying strategy until achievement of the equation [28]:

$$
\begin{aligned}
& \widehat{u_{i}}(t)=k_{i} \mu_{i}(t) J_{i}(t), \\
& u_{i}(t)=\widehat{u}_{i}(t)+\mu_{i}(t) .
\end{aligned}
$$

where $\mu(t)=a_{i} \sin \left(\varphi_{i} t+\varphi_{i}\right), k_{i}, a_{i}, \varphi_{i}>0$ and $\in\{1,2\}$. 
Decision-making frequencies in this case take the form:

$$
\omega_{i}=\omega \bar{\omega}_{i},
$$

where $\omega$ is the positive real number and $\varpi_{i}$ is the positive rational number. This form is convenient for convergence analysis.

We performed simulation calculations to determine the overall type of graphs, which correspond to the obtained prices and profit levels obtained when players implemented the investigated strategies.

We defined the following parameters to model the process of reducing the system to the Nash equilibrium: $S_{d}=100$, $p=0.2, m_{1}=m_{2}=30, a_{1}=0.075, a_{2}=0.05, k_{2}=2, k_{2}=5, \omega_{1}=$ $=26.75 \mathrm{rad} / \mathrm{s}, \omega_{2}=22 \mathrm{rad} / \mathrm{s}, u_{1}(0)=\hat{\mathrm{u}}_{1}(0)=50, u_{2}(0)=\hat{\mathrm{u}}_{2}(0)=$ $=110 / 3$. It is not possible to achieve the Nash equilibrium in a trivial way $u_{2}(0)=u_{2}$, therefore, $u_{2}(t)$ increases initially before decreasing to $u_{2}^{\prime}$, due to the total system dynamics. Unlike a smooth solution, enterprise profits are also guaranteed to converge on the Nash equilibrium using a standard parallel-action update scheme [28]:

$$
\begin{aligned}
& u_{1}^{(k+1)}=\frac{1}{2}\left(u_{2}^{(k)}+m_{1}+S_{d} p\right), \\
& u_{2}^{(k+1)}=\frac{1}{2}\left(u_{1}^{(k)}+m_{2}\right) .
\end{aligned}
$$

It is necessary to know the overall demand and a consumer preference parameter for $P_{1}$. In fact, $\mathrm{P}_{1}$ should know almost all relevant modeling information [28]. In contrast, an enterprise needs only measure a value of their own payoff functions, $J_{1}$ and $J_{2}$, at application of the extreme search algorithm. Such calculation establishes local results using a theory that is a synthesis of two different theories: a nonlinear Floquet theory and perturbation theory [34].

However, it is possible to calculate a non-local result for this example semi-globally, according to the methodology for static games with quadratic payoff functions. It is possible to apply the methods used for general convex systems for a detailed analysis of the nonlocal convergence of controllers for the search for extremums [35].

Let us consider the following system to solve the problem of the search for the state of the Nash equilibrium in a non-quadratic game with players, who use an extremum search strategy based the equations calculated previously:

$$
\begin{aligned}
& x_{1}=-4 x_{1}+x_{1} x_{2}+u_{2}, \\
& x_{2}=-4 x_{2}+u_{2}, \\
& J_{1}=-16 x_{1}^{2}+8 x_{1}^{2} x_{1}-x_{1}^{2} x_{2}^{2}-6 x_{1} x_{2}^{2}+ \\
& +\left(24+\frac{5}{32}\right) x_{1} x_{2}-\frac{5}{8} x_{1}, \\
& J_{2}=-64 x_{2}^{3}+48 x_{1} x_{2}-12 x_{1} x_{2}^{2},
\end{aligned}
$$

we determine its equilibrium state from formula:

$$
\left(\bar{x}_{1}, \bar{x}_{2}\right)=\left(\frac{4 u_{1}}{16-u_{2}}, \frac{u_{2}}{4}\right) .
$$

Jacobian determinant has a Hurwitz property at such equilibrium if $u_{2}<16$. Thus, the equilibrium state is locally exponentially stable, but not for all $\left(u_{2}, u_{2}\right) \in R^{2}$. As we noted earlier, we set the restrictive requirement of local exponential stability for all $u \in R^{N}$ just for convenience of designation, and in fact this is only an assumption for players. So, in this example, player actions are limited to:

$$
U=\left\{\left(u_{1}, u_{2}\right) \in R^{2} \mid u_{1}, u_{2} \geq 0, u_{2}<16\right\} .
$$

When $x=\bar{x}$, the profit function takes the form

$$
\begin{aligned}
& J_{1}=-u_{1}^{2}+\frac{3}{2} u_{1} u_{2}-\frac{5}{32} x_{1}^{2} x_{2}^{2}-6 x_{1} x_{2}^{2}+ \\
& +\left(24+\frac{5}{32}\right) x_{1} x_{2}-\frac{5}{8} x_{1} \\
& J_{2}=-64 x_{2}^{3}+48 x_{1} x_{2}-12 x_{1} x_{2}^{2} .
\end{aligned}
$$

The potential surfaces of the payoff function with their associated response curves that lie in the action set, and the extremes $\partial J_{i} / \partial u_{S}=0$ that lie outside $U$, overlap each other.

The reaction curves have two intersections in the middle. They correspond to the two Nash equilibria: $\left(u_{1}^{\prime \prime}, u_{2}^{\prime \prime}\right)=(25 / 64,5 / 8)$ and $\left(v_{1}^{\prime \prime}, v_{2}^{\prime \prime}\right)=(1 / 64,1 / 8)$.

There are assumptions made in $u$ ", that there is at least one, possibly multiple, isolated stable Nash equilibrium $u^{\prime \prime}=\left[u_{1}^{\prime \prime}, \ldots, u_{N}^{\prime \prime}\right]$, such that all $i \in\{1, \ldots, N\}$; and that matrix

$$
\wedge\left[\begin{array}{cccc}
\frac{\partial^{2}\left(h_{1} \times l\right)\left(u^{*}\right)}{\partial u_{1}^{2}} & \frac{\partial^{2}\left(h_{1} \times l\right)\left(u^{*}\right)}{\partial u_{1} \partial u_{2}} & \cdots & \frac{\partial^{2}\left(h_{1} \times l\right)\left(u^{*}\right)}{\partial u_{1} \partial u_{N}} \\
\frac{\partial^{2}\left(h_{1} \times l\right)\left(u^{*}\right)}{\partial u_{1} \partial u_{2}} & \frac{\partial^{2}\left(h_{2} \times l\right)\left(u^{*}\right)}{\partial u_{2}^{2}} & & \\
\vdots & & \ddots & 1 \\
\frac{\partial^{2}\left(h_{N} \times l\right)\left(u^{*}\right)}{\partial u_{1} \partial u_{N}} & & & \frac{\partial^{2}\left(h_{N} \times l\right)\left(u^{*}\right)}{\partial u_{N}^{2}}
\end{array}\right],
$$

is strictly diagonally dominant and corresponds to the criterion of the stability criterion of a matrix, which implies $u$ " stability, whereas in v", these assumptions are violated, as it should be, since further analysis shows that $v$ " is the unstable Nash equilibrium.

The reaction curves also intersect at the limit of set of $\partial U$ actions in $(0,0)$, which means that the game has Nash equilibrium at the limit, which players can search for depending on the initial conditions of a game.

It is possible to apply a modified Nash search strategy, which uses projection as shown in the study [36], to keep players within the action set.

We use the previously calculated model (11), (12) to study the strategy of actions of agricultural enterprises in the wholesale market of vegetable products:

$$
\begin{aligned}
& \widehat{u_{i}}(t)=k_{i} \mu_{i}(t) J_{i}(t), \\
& u_{i}(t)=\widehat{u}_{i}(t)+\mu_{i}(t) .
\end{aligned}
$$

We build a system based on the above:

$$
\begin{aligned}
& x_{1}=a_{1} u_{1}+a_{2} u_{2}-a_{0} x_{1}, \\
& x_{2}=b_{1} x_{1}-b_{2} x_{2} .
\end{aligned}
$$


We calculate the payment (profit) functions:

$$
\begin{aligned}
& J_{1}=d_{1} u_{1} x_{1}-\frac{d_{2} u_{1}^{2}}{u_{2}^{2}}, \\
& J_{2}=h_{1} x_{1}+h_{2} x_{2}+h_{3} u_{2} x_{1}-\frac{h_{4} u_{2}^{2}}{u_{1}^{2}},
\end{aligned}
$$

where $a_{i}, b_{i}, h_{i}, d_{i}$ are constant non-negative coefficients; $x_{1}=0, x_{2}=0$ at the point $\left(\overline{x_{1}}, \overline{x_{2}}\right)$ is the equilibrium state.

We find this point:

$$
\begin{aligned}
& \overline{x_{1}}=\frac{a_{1}}{a_{0}} u_{1}+\frac{a_{2}}{a_{0}} u_{2}=c_{1} u_{1}+c_{2} u_{2}, \\
& \overline{x_{2}}=\frac{a_{1} b_{1}}{a_{0} b_{2}} u_{1}+\frac{a_{2} b_{1}}{a_{0} b_{2}} u_{2}=g_{1} u_{1}+g_{2} u_{2} .
\end{aligned}
$$

We calculate eigennumbers of the matrix:

$$
A=\left(\begin{array}{cc}
-a_{0} & 0 \\
b_{1} & -b_{2}
\end{array}\right): \lambda_{1}=-a_{0}, \lambda_{2}=-b_{2} .
$$

The numbers are negative, so the system is stable.

We use the found point in the payment function (that is, we assumed that the function is in the equilibrium state, which will be close to the real state after some time):

$$
\begin{aligned}
& J_{1}=d_{1} u_{1}\left(c_{1} u_{1}+c_{2} u_{2}\right)-\frac{d_{2} u_{1}^{2}}{u_{2}^{2}}, \\
& J_{2}=h_{1}\left(c_{1} u_{1}+c_{2} u_{2}\right)+h_{2}\left(g_{1} u_{1}+g_{2} u_{2}\right)+ \\
& +h_{3} u_{2}\left(c_{1} u_{1}+c_{2} u_{2}\right)-\frac{h_{4} u_{2}^{2}}{u_{1}^{2}} .
\end{aligned}
$$

We find $\left(l_{1}, l_{2}\right)$ reaction curves:

$$
\frac{\partial J_{1}}{\partial u_{1}}=2 d_{1} c_{1} u_{1}+d_{1} c_{2} u_{2}-\frac{2 d_{2} u_{1}}{u_{2}^{2}}=0 .
$$

Therefore:

$$
u_{1}=l_{1}\left(u_{2}\right)=\frac{d_{1} c_{2} u_{2}^{3}}{2 d_{2}-2 d_{1} c_{1} u_{2}^{2}} .
$$

Similarly, we calculate:

$$
\begin{aligned}
& \frac{\partial J_{2}}{\partial u_{2}}=h_{1} c_{2}+h_{2} g_{2}+h_{3} c_{1} u_{1}+2 h_{3} c_{2} u_{2}-2 \frac{h_{4} u_{2}}{u_{1}^{2}}=0, \\
& u_{2}=l_{2}\left(u_{1}\right)=\frac{\left(h_{1} c_{2}+h_{2} g_{2}+h_{3} c_{1} u_{1}\right) u_{1}^{2}}{2 h_{4}-2 h_{3} c_{2} u_{1}^{2}} .
\end{aligned}
$$

Fig. 1 shows an arbitrary example of the graphical representation of reaction curves of the studied process.

The matrix is derived from the assumption. The matrix is strictly diagonally dominant and, therefore, it is uncertain $-\Lambda$ :

$$
\Lambda=\left(\begin{array}{cc}
\frac{\partial J_{1}^{2}}{\partial u_{1}^{2}} & \frac{\partial J_{1}^{2}}{\partial u_{1} \partial u_{2}} \\
\frac{\partial J_{2}^{2}}{\partial u_{1} \partial u_{2}} & \frac{\partial J_{2}^{2}}{\partial u_{2}^{2}}
\end{array}\right),
$$

$$
\frac{\partial J_{1}^{2}}{\partial u_{1}^{2}}=2 d_{1} c_{1}-\frac{2 d_{2}}{u_{2}^{2}}
$$

$$
\begin{gathered}
\frac{\partial J_{1}^{2}}{\partial u_{1} \partial u_{2}}=d_{1} c_{2}+\frac{4 d_{2} u_{1}}{u_{2}^{3}}, \\
\frac{\partial J_{2}^{2}}{\partial u_{1} \partial u_{2}}=h_{3} c_{1}+\frac{4 h_{4} u_{2}}{u_{1}^{3}},
\end{gathered}
$$$$
\frac{\partial J_{2}^{2}}{\partial u_{2}^{2}}=2 h_{3} c_{2}-\frac{2 h_{4}}{u_{1}^{2}}
$$

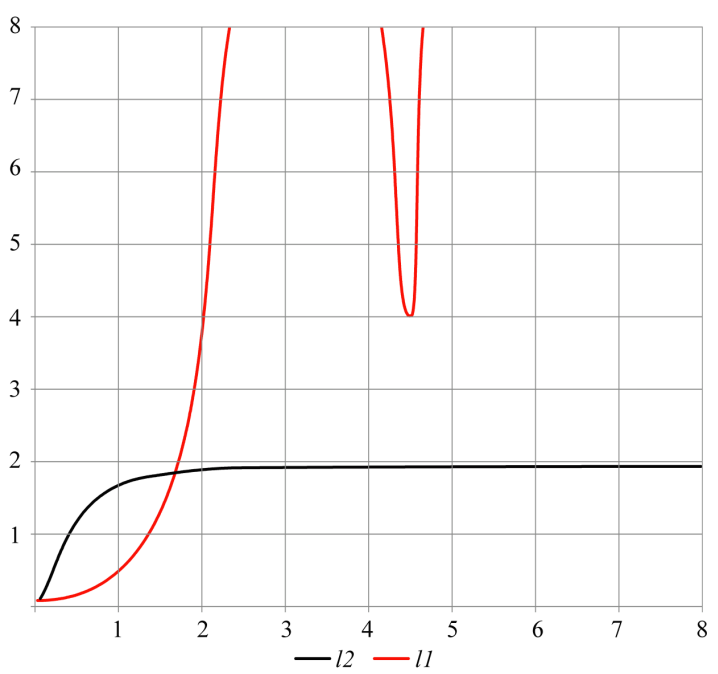

Fig. 1. Graph of $/ 1$, and $R$ reaction curves

It is necessary to take into account the basic parameters and coefficients of a model based on market research to determine a state of the Nash equilibrium. The main parameters are preferences of customers, market boundaries, and a market influence, an impact of product quality, costs and volume of one-time batch on a value of an enterprise price.

We calculated the following coefficients in numerical terms for simulation calculations to determine a general type of graphs that correspond to the obtained prices and profit levels, when agrarian enterprises (players) implement the investigated strategies. The starting price -1.00 . The determined coefficients $a_{1}=5, a_{2}=1, a_{0}=10$, where $a_{1}$ is the current position of an enterprise in the market (customer preferences), $a_{2}$ and $a_{0}$ are the market boundaries, respectively. $b_{1}, b_{2}$, where $b_{1}=5, b_{2}=1$ are the influences on formation of profit of other players in the market in terms of the market and of an enterprise, respectively. $d_{1}, d_{2}$ where $d_{1}=1, d_{1}$ are unknown coefficients of an influence on the pricing of other players in the market. The coefficient of an influence of quality of products presented for sale on a value of an enterprise price $-h_{1}=0.15$. The coefficient of an influence of a volume of a one-time batch of products on a value of an enterprise price $h_{2}=0.2$. The coefficient of an influence of a marginal cost of production on a value of an enterprise price $h_{3}=0.65$. The coefficient of an influence of fixed costs on production on a value of an enterprise price $h_{4}=1.0$.

We found an intersection of $l_{1}\left(u_{2}\right)$ and $l_{2}\left(u_{1}\right)$ reaction curves at the point $(1.77,1.36)$ among the found solutions in the used model. It is the only intersection, which satisfies us in the admissible region of strategies, it is the Nash equilibrium (Fig. 2). 


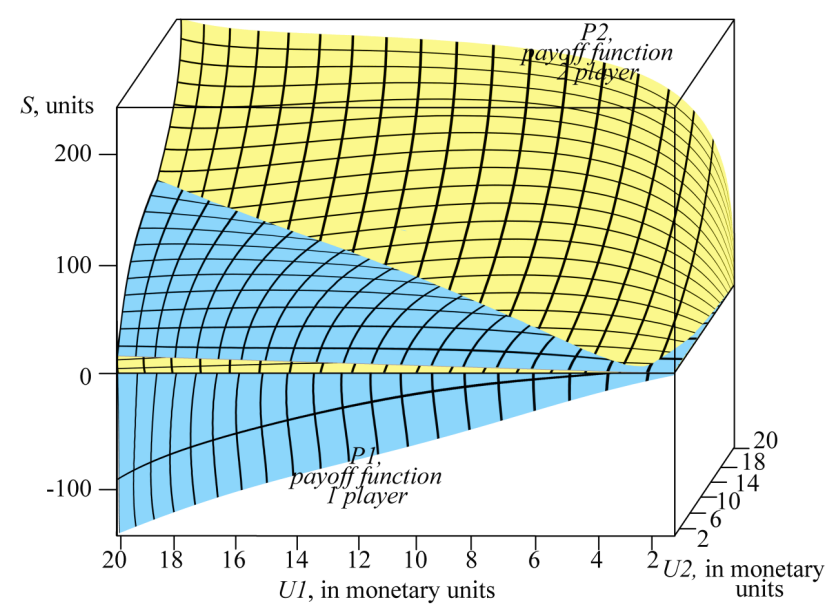

Fig. 2. Potential surfaces of payoff function

The investigated matrix is negatively defined if the assumption that $\Lambda$ matrix has a diagonal dominance is correct,

$$
\frac{\partial J_{1}^{2}}{\partial u_{1}^{2}}<0, \frac{\partial J_{2}^{2}}{\partial u_{2}^{2}}<0
$$

The above numerical calculations demonstrate the effectiveness of further studies on the choice of optimal movement options and ways of their achievement, which is possible within a certain set of methodological guidelines.

\section{Discussion of results of forecasting a search for the Nash equilibrium state in a non-quadratic game}

We propose an algorithm of optimization of a strategy of behavior of players in static non-cooperative games with two players. (1) defines that the equilibrium point is $n$-tuple $\$$, and a mixed strategy maximizes payoff of each player if strategies of other players are fixed. The algorithm consists of two steps. The first step is choosing of $n$-set of mixed strategies of all players including non-empty ones, convex ones and compact ones, and the payoff function of each player is defined as quasi-concave. As a value of a player's payoff function in a situation when a mixed strategy uses a pure strategy, (2) determines the expected utility.

A player cannot determine a priori whether his initial action is correct enough to guarantee convergence, so sequences of choices throughout replace a game pure player's strategies Therefore, in the second stage, we verify a statement that a game has Nash equilibrium point in pure strategies (3).

It is necessary to achieve local convergence of results to implement the algorithm, since payoff functions can be non-quadratic and there can be multiple isolated Nash equilibria. However, practical semi-global convergence can be achieved for quadratic payoffs.

We performed the calculation of possible strategies of actions of enterprises in the market, where players measure only their own payoff values, which makes it possible to determine the main external effects, which arise. We determined a value of players own payment functions at using the extremum search algorithm in (11), (12). A non-local result was calculated for static games with quadratic payoff functions using numerical values in the numerical solution.
An analysis of the non-local convergence of regulators of the extremum search applied to general convex systems showed that potential surfaces of the payoff function with its associated response curves, which lie in a set of actions and determined extremal that lie outside $U$, overlap each other (16), (17), for non-quadratic payoff functions.

When a closed and restricted set of actions $U \subset \mathbb{R}^{N}$, limits players' actions, reaction curves also intersect at the boundary of $\partial U$ set of actions $(0,0)$. This means that the game has Nash equilibrium at the boundary (18), which players search for depending on the initial conditions of a game.

The determined equilibrium may be unstable, because the rule that each diagonal element is strictly greater than the sum of all other elements of a line is not fulfilled at the equilibrium point. Most likely, it is still a stable equilibrium, but it is difficult to check, because it is only a mathematical conclusion on the results of the solution of the system.

The direction for further research may be development of methods for improvement of the quality of finding of an optimal strategy for an agricultural enterprise in the wholesale market of vegetable products.

\section{Conclusions}

1. The application of the proposed algorithm implements a random mechanism according to probability distribution into a set of possible actions in a game situation, when each player chooses a mixed strategy independently of other players.

The algorithm uses pure player strategies at the initial stage of a game. He chooses them randomly from a set of actions. Sequences of a choice, which are uniquely consistent with its pure strategies, replace certain strategies at each step in the implementation of the algorithm.

The payoff function used in the definition of the end game above has the only extension on $n$-sets of mixed strategies linear to each player's mixed strategy. Thus, the algorithm gives possibility to determine a dominant strategy of a player. An algorithm is implemented if a value of a target function is not worse than a value of a target function at choosing of a pure strategy at random choices of their strategies by all other players.

A strategy of each player's actions is optimal against of strategies of other players at the implementation of the proposed algorithm. The implementation of the strategy, in particular, makes it possible to solve problems of optimization of a strategy of an enterprise in a sale of products on the market.

2. We used iterative algorithms to find the Nash equilibrium with projection since most problems do not have a solution in analytical form because of the requirement of discretion of arguments. We defined a set of necessary actions for players to calculate equilibria in a general class of non-quadratic convex polyhedra by the integrated use of numerical methods to ensure that their actions remain appropriate.

It is not possible to achieve the convergence to the Nash equilibrium trivially as long as there is first an increase and then a decrease in the calculated $J_{i}(t)$ parameters due to the overall dynamics of the equation system. Application of deterministic search for the extremum of functions with sinusoidal perturbations made possible to solve the system 
of nonlinear equations, which gives an enterprise possibility to set its prices at the optimal level.

The Nash equilibrium calculation using the proposed algorithm of actions makes possible:

- identification of typical situations that arise over time, until achievement of the equations, with guaranteed quantitative and qualitative characteristics converged to the Nash equilibrium;
- calculation of the non-local result semi-globally according to the methodology for static games with quadratic payoff functions.

The used approach provides enterprises with a possibility to simplify their decision-making calculations for actions of an enterprise in the market by measurement of their own payoff values only, without requiring a potential evaluation of uncertain parameters.

\section{References}

1. Sievidova, I. A. (2017). Factors affecting the economic management efficiency of agricultural enterprises in Ukraine. Problems and Perspectives in Management, 15 (2), 204-211. doi: https://doi.org/10.21511/ppm.15(2-1).2017.04

2. Brown, G. W. (1951). Iterative solutions of games by fictitious play. Activity Analysis of Production and Allocation. Wiley, $374-376$.

3. Cournot, A. (1938). Recherches sur les PrincipesMathématiques de la Théorie des Richesses. Paris, France: Hachette.

4. Shamma, J. S., Arslan, G. (2005). Dynamic fictitious play, dynamic gradient play, and distributed convergence to Nash equilibria. IEEE Transactions on Automatic Control, 50 (3), 312-327. doi: https://doi.org/10.1109/tac.2005.843878

5. Zhu, M., Martínez, S. (2010). Distributed coverage games for mobile visual sensor networks. SIAM J. Control Optim. Available at: https://arxiv.org/pdf/1002.0367.pdf

6. Babenko, V., Nazarenko, O., Nazarenko, I., Mandych, O., Krutko, M. (2018). Aspects of program control over technological innovations with consideration of risks. Eastern-European Journal of Enterprise Technologies, 3 (4 (93)), 6-14. doi: https:// doi.org/10.15587/1729-4061.2018.133603

7. Li, J. (2018). Infinitely split Nash equilibrium problems in repeated games. Fixed Point Theory and Applications, 2018 (1). doi: https://doi.org/10.1186/s13663-018-0636-1

8. Duffy, J. (2015). Game Theory and Nash Equilibrium. A project submitted to the Department of Mathematical Sciences in conformity with the requirements for Math 4301 (Honours Seminar). Lakehead University, 37. Available at: https:// www.lakeheadu.ca/sites/default/files/uploads/77/images/Duffy\%20Jenny.pdf

9. Ye, M., Hu, G. (2017). Game Design and Analysis for Price-Based Demand Response: An Aggregate Game Approach. IEEE Transactions on Cybernetics, 47 (3), 720-730. doi: https://doi.org/10.1109/tcyb.2016.2524452

10. Zeng, X., Chen, J., Liang, S., Hong, Y. (2019). Generalized Nash equilibrium seeking strategy for distributed nonsmooth multi-cluster game. Automatica, 103, 20-26. doi: https://doi.org/10.1016/j.automatica.2019.01.025

11. Liang, S., Yi, P., Hong, Y. (2017). Distributed Nash equilibrium seeking for aggregative games with coupled constraints. Automatica, 85, 179-185. doi: https://doi.org/10.1016/j.automatica.2017.07.064

12. Hefti, A. (2017). Equilibria in symmetric games: Theory and applications. Theoretical Economics, 12 (3), $979-1002$. doi: https://doi.org/10.3982/te2151

13. Zeng, J., Wang, Q., Liu, J., Chen, J., Chen, H. (2019). A Potential Game Approach to Distributed Operational Optimization for Microgrid Energy Management With Renewable Energy and Demand Response. IEEE Transactions on Industrial Electronics, 66 (6), 4479-4489. doi: https://doi.org/10.1109/tie.2018.2864714

14. Zhou, W., Koptyug, N., Ye, S., Jia, Y., Lu, X. (2016). An Extended N-Player Network Game and Simulation of Four Investment Strategies on a Complex Innovation Network. PLOS ONE, 11 (1), e0145407. doi: https://doi.org/10.1371/journal. pone. 0145407

15. Gordji, M. E., Askari, G. (2018). Hyper-Rational Choice and Economic Behaviour. Advances in mathematical finance \& applications, 3 (3), 69-76. doi: http://doi.org/10.22034/amfa.2018.544950

16. Caruso, F., Ceparano, M. C., Morgan, J. (2018). Uniqueness of Nash equilibrium in continuous two-player weighted potential games. Journal of Mathematical Analysis and Applications, 459 (2), 1208-1221. doi: https://doi.org/10.1016/ j.jmaa.2017.11.031

17. Li, X. (2018). Existence of Generalized Nash Equilibrium in n-Person Noncooperative Games under Incomplete Preference. Journal of Function Spaces, 2018, 1-5. doi: https://doi.org/10.1155/2018/3737253

18. Kreuzberg, F., Hein, N., Rodrigues Junior, M. M. (2015). Teoria dos Jogos: Identificação do Ponto de Equilíbrio de Nash em Jogos Bimatriciais em Indicadores Econ micos e Sociais. Future Studies Research Journal: Trends and Strategies, 7 (2), 42. doi: https://doi.org/10.24023/futurejournal/2175-5825/2015.v7i2.196

19. Häfner, S., Nöldeke, G. (2016). Payoff Shares in Two-Player Contests. Games, 7 (3), 25. doi: https://doi.org/10.3390/g7030025

20. Wu, F., Ma, J. (2014). The Chaos Dynamic of Multiproduct Cournot Duopoly Game with Managerial Delegation. Discrete Dynamics in Nature and Society, 2014, 1-10. doi: https://doi.org/10.1155/2014/206961 
21. 21. Madandar, F., Haghayeghi, S., S. Vaezpour, M. (2018). Characterization of Nash Equilibrium Strategy for Heptagonal Fuzzy Games. International Journal of Analysis and Applications, 16 (3), 353-367. doi: https://doi.org/10.28924/2291-863916-2018-353

22. Chattopadhyay, S., Mitka, M. M. (2019). Nash equilibrium in tariffs in a multi-country trade model. Journal of Mathematical Economics, 84, 225-242. doi: https://doi.org/10.1016/j.jmateco.2019.07.011

23. Christodoulou, G., Gairing, M., Giannakopoulos, Y., Spirakis, P. G. (2019). The Price of Stability of Weighted Congestion Games. SIAM Journal on Computing, 48 (5), 1544-1582. doi: https://doi.org/10.1137/18m1207880

24. Rosenthal, R. W. (1973). A class of games possessing pure-strategy Nash equilibria. International Journal of Game Theory, 2 (1), 65-67. doi: https://doi.org/10.1007/bf01737559

25. Hou, F., Zhai, Y., You, X. (2020). An equilibrium in group decision and its association with the Nash equilibrium in game theory. Computers \& Industrial Engineering, 139, 106138. doi: https://doi.org/10.1016/j.cie.2019.106138

26. Babichenko, Y. (2014). Query complexity of approximate nash equilibria. Available at: https://arxiv.org/pdf/1306.6686v3.pdf

27. Nisan, N., Roughgarden, T., Tardos, E., Vazirani, V. V. (Eds.) (2007). Algorithmic Game Theory. Cambridge University Press. doi: https://doi.org/10.1017/cbo9780511800481

28. Frihauf, P., Krstic, M., Basar, T. (2012). Nash Equilibrium Seeking in Noncooperative Games. IEEE Transactions on Automatic Control, 57 (5), 1192-1207. doi: https://doi.org/10.1109/tac.2011.2173412

29. Fisher, R. (1991). Getting to yes: negotiating agreement without giving in. Boston: Houghton Mifflin, 200.

30. Mak-Kinsi, Dzh. (1960). Vvedenie v teoriyu igr. Moscow: Gos. izd-vo fiz-mat literatury, 420.

31. Collard-Wexler, A., Gowrisankaran, G., Lee, R. S. (2019). "Nash-in-Nash” Bargaining: A Microfoundation for Applied Work. Journal of Political Economy, 127 (1), 163-195. doi: https://doi.org/10.1086/700729

32. Hubko, M. V., Novykov, D. A. (2005). Teoryia yhr v upravlenyy orhanyzatsyonnыmy systemamy. M., 168.

33. Nash, J. F., Shapley, L. S. (1950). A Simple Three-Person Poker Game. Princeton University Press.

34. Sarychev, A. V. (2001). Lie- and chronologico-algebraic tools for studying stability of time-varying systems. Systems \& Control Letters, 43 (1), 59-76. doi: https://doi.org/10.1016/s0167-6911(01)00090-1

35. Tan, Y., Nešić, D., Mareels, I. (2006). On non-local stability properties of extremum seeking control. Automatica, 42 (6), 889-903. doi: https://doi.org/10.1016/j.automatica.2006.01.014

36. Krstic, M., Kanellakopoulos, I., Kokotovic, P. (1995). Nonlinear and Adaptive Control Design. Wiley-Interscience, 576. 